\title{
Influence of the milling strategies on roundness of machined surfaces
}

\author{
Ján Varga ${ }^{1, *}$, Emil Spišák ${ }^{2}$
}

1 Faculty of Mechanical Engineering, Technical University of Košice, Department of Engineering Technologies and Materials, Košice, Slovakia, e-Mails: jan.varga@tuke.sk

2 Faculty of Mechanical Engineering, Technical University of Košice, Department of Engineering Technologies and Materials, Košice, Slovakia, e-Mails: emil.spisak@tuke.sk

\begin{abstract}
The paper deals with influence of various milling strategies on the accuracy of produced part (circle pocket). One of the most important factors in milling, which influences surface quality is milling strategy. Sample design was created in CAD system Solidworks. Milling tool paths were created in CAM system SolidCAM. Utilization of CAM systems in product design helps to satisfy demands on the quality of produced part from the point of view product accuracy. Surface quality is influenced by several process parameters such as tool diameter, cutting parameters, work-piece material properties, clamping of the part, milling strategy and others. In this article, milling strategies Constant Z, Pocket, Pocket auto borders and Spiral strategy and their influence on surface quality of produced parts were evaluated. In the first step simulations of different toolpaths were conducted. The results obtained from simulations were compared and evaluated. Milling strategies mentioned above were used in experimental production of the parts. Surface quality and deviations (roundness, cylindricity and shape deviations) of produced experimental parts were measured on CMM device. Experimentally measured values were evaluated and analysed.
\end{abstract}

Keywords: SolidCAM; milling strategies; geometrical characteristics

\section{Introduction}

CNC milling is today the most effective, productive, and flexible manufacturing method for machining of different surfaces [1]. The characteristic feature of the milling process is that each milling cutter tooth removes its share of the stock in the form of small individual chips [2]. Toolpath strategies are important in CNC milling. These strategies allow optimization of milling tool motion during milling process and by this motion optimization it possible to obtain required surface properties mainly accuracy [3]. The chosen strategy to generate the tool path can influence important parameters (machining time, cutting forces, length of the tool path, surface roughness). However, strategies of tool motion are one of controlling factors which lead to the final quality of complex product. Surface quality is influenced by several process parameters such as tool diameter, cutting parameters, work-piece material, clamping of part, milling strategy and others.

More than $80 \%$ of machining of mechanical parts can be performed using $2.5 \mathrm{D}$ milling. The reason for it is that most of the parts consist of faces parallel or perpendicular to a single plane, also freeform objects are usually produced from a raw stock by $2.5 \mathrm{D}$ roughing and 3D or 5D finishing [4].

2.5D machining strategy which aims to clear out the totally of a pre-defined contour is called "pocketing" and the contour is called a "pocket" [5]. Pocketing is one of the most

* Corresponding author: Ján Varga, E-mail address: jan.varga@tuke.sk 
common machining operations in aeronautic and automotive industry since it is employed during the roughing stage of molds and dies manufacturing [6].

CAM software for the programming of CNC milling machine provides the possibility of producing various toolpaths for the tool. The characteristic shape of the toolpath is described by the term milling strategy [7]. Mikó et. al [8] conducted experiments regarding measurement of flatness and surface roughness when face milling and turning. The accuracy analysis of the roundness measurement with coordinate measuring machines was published by Gapinski et. al. [9]. Mr. Zheng et. al. [10] conducted research of the on-line evaluating the cylindricity deviation. Another work regarding measurement of flatness deviation was published by Nadolny and Kaplonek [11]. This research was oriented on measuring flatness of austenitic stainless-steel work-pieces after efficient surface machining. The work of Salah and Mohamd [12] was oriented on dimensional and geometrical form accuracy of circular pockets manufactured for aluminium, copper and steel materials.

\section{Experimental work}

\subsection{Sample Design - work-piece}

In this work four identical work-pieces were produced. The sample design of the part was created in CAD system SolidWorks for comparison of different milling strategies. The work-pieces were made of aluminium alloy (AlCu4Mg). Dimensions and geometry of the blocks are shown in Fig. 1.
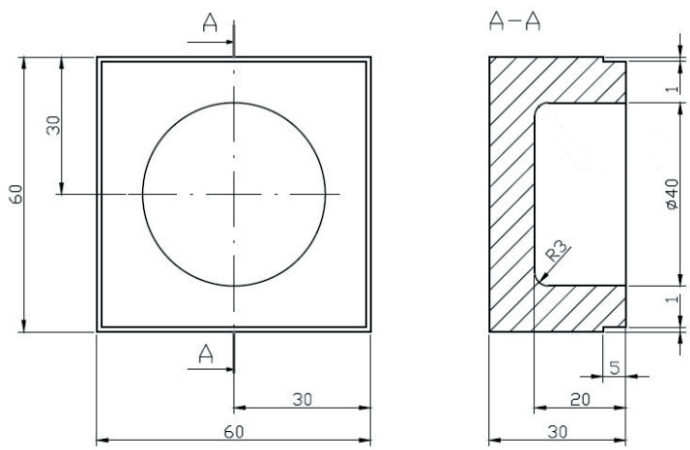

Figure 1: Experimental part scheme.

Table 1 shows the chemical composition of the aluminium alloy and Table 2 describes mechanical properties of this alloy.
Table 1: Chemical composition of Al-Cu-Mg alloy (wt\%).

\begin{tabular}{|l|l|l|l|l|l|l|l|}
\hline Cu & Mg & Fe & Si & Mn & Ti & Zn & Al \\
\hline 4.25 & 0.00 & 0.26 & 0.24 & 0.3 & 0.02 & 0.04 & Bal. \\
\hline
\end{tabular}

Table 2: Selected mechanical properties of Al-Cu-Mg alloy.

\begin{tabular}{|l|l|l|}
\hline $\begin{array}{l}\text { Tensile strength } \\
\text { [MPa] }\end{array}$ & $\begin{array}{l}\text { Yield strength } \\
\text { [MPa] }\end{array}$ & Hardness [HB] \\
\hline 101.89 & 86.69 & 90.20 \\
\hline
\end{tabular}

The shape of parts is made in three stages: roughing, semi-finishing and finishing. Roughing and semi-finishing strategies had the same parameters for all four specimens. The reason for it was that, the same initial conditions have been reached before conducting different finishing strategies.

\subsection{Sample Design - machining device, cutting tools and cutting parameters}

The milling was done by 3 axis CNC machining centre EMCO Concept Mill 155 which is shown in Fig. 2 with control system Heidenhain TNC 426. CNC programs were generated by CAM system - SolidCAM. Milling machine has following parameters: Travel X: 300 mm, Travel Y: 200 mm, Travel Z: $300 \mathrm{~mm}$, max. work-piece weight: $20 \mathrm{~kg}$, spindle power: $2.5 \mathrm{~kW}$, spindle speed $n=5000 \mathrm{~min}^{-1}$.

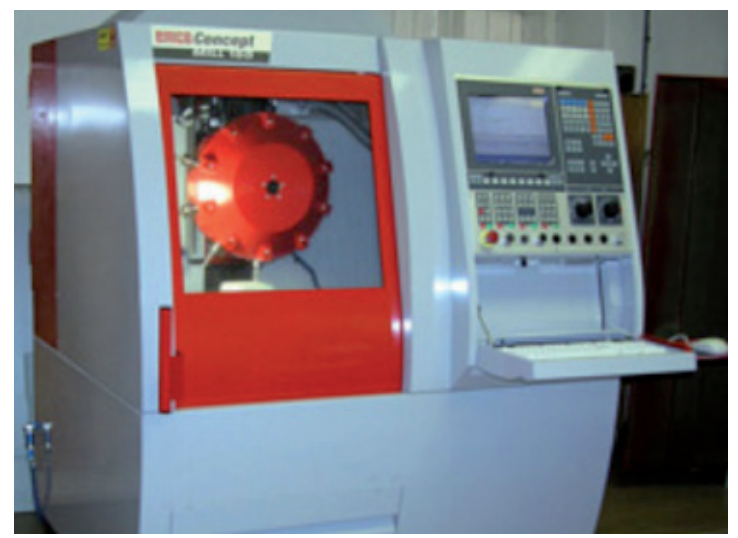

Figure : EMCO Concept Mill 155 machine.

Four milling strategies namely Constant Z, Constant Step - Pocket, Constant Step - Pocket Auto Border and Spiral strategies have been used for finishing operations. In all samples face milling was done using end mill $D=18 \mathrm{~mm}$, and axial depth of cut $0.2 \mathrm{~mm}$. Cutting conditions for aluminium alloy machining have been chosen according to the tool manufacturers recommendation:

- Face milling - end mill D = 18 mm by Korloy AMS 2018S, 2 
replaceable uncoated carbide inserts, cutting speed $v_{c}=271 \mathrm{~m} \cdot \mathrm{min}^{-1}$, feed per tooth $\mathrm{fz}=0.1 \mathrm{~mm}$.

- Roughing - end mill D = $18 \mathrm{~mm}$ by Korloy AMS 2018S, 2

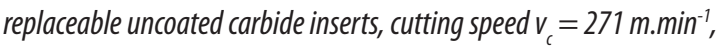
feed $f_{z}=0.1 \mathrm{~mm}$.

- Semi-finishing - ball mill $D=8 \mathrm{~mm}$ by ZPS-FN, 4 teeth, material HSS Co8, cutting speed $v_{c}=123 \mathrm{~m}_{\mathrm{min}} \mathrm{min}^{-1}$, feed $\mathrm{fz}=0.024 \mathrm{~mm}$.

- Finishing - ball mill D $=6 \mathrm{~mm}, 2$ teeth, tool material HSS Co8, cutting speed $v_{c}=92 \mathrm{~m} \cdot \mathrm{min}^{-1}$, feed $f_{z}=0.022 \mathrm{~mm}$.

The shape of parts is obtained in three stages: roughing, semi-finishing and finishing. The following cutting conditions for roughing operation were used: tool path overlapping op $=0.50 \mathrm{~mm}$ and depth of cut $a_{p}=1 \mathrm{~mm}$. Semi-finishing depth of cut within $a_{p}=0.2-0.5 \mathrm{~mm}$. Depth of cut is defined by CAM system in dependence on surface orientation to reach the selected scallop height $\mathrm{SH}=0.5 \mathrm{~mm}$. After semi-finishing allowance $\mathrm{h}=0.2 \mathrm{~mm}$ has been left for all surfaces.

\section{Results and Discussion}

\subsection{Finishing operation}

Comparison of four different strategies and their influence on surface quality of produced part (circle pocket) have been conducted. Surface quality is influenced by several process parameters such as tool diameter, cutting parameters, work-piece material properties, clamping of the part, milling strategy and others. One of the most important factors is milling strategy, which influences produced part accuracy.

For finishing operation, the following milling strategies were used:

- Constant Z

- Constant Step - Pocket

- Constant Step - Pocket auto border

- Spiral

Constant Z strategy

Strategy Constant $Z$ has used variable depth of cut within ap $=0.1-0.4 \mathrm{~mm}$. It is defined by CAM system in dependence on surface orientation and max. tool path overlapping was $0.1 \mathrm{~mm}$. The generated toolpath for finishing strategy Constant $Z$ is shown in Fig. 3 .

The tool begins the finishing operation with the wall of pocket and gradually moves along the paths toward the bottom of the pocket. Bottom machining in this strategy is done from the bottom to its centre. For machining the bottom of the pocket with the Z-constant finishing strategy, the

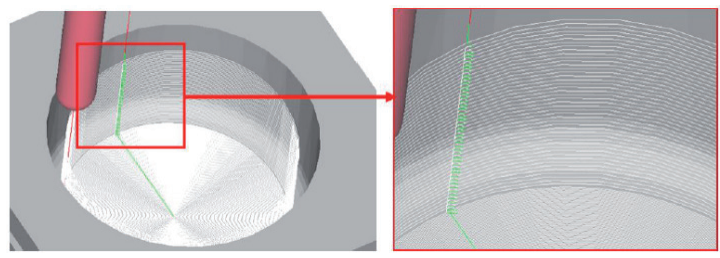

Figure 3: Tool toolpath for finishing operation - Constant Z. tool paths are a circle with constant steps, which are formed from concentric circles. The comparison between simulation results obtained in CAM system SolidCAM and experimental results of machined surface is shown in Fig. 4.

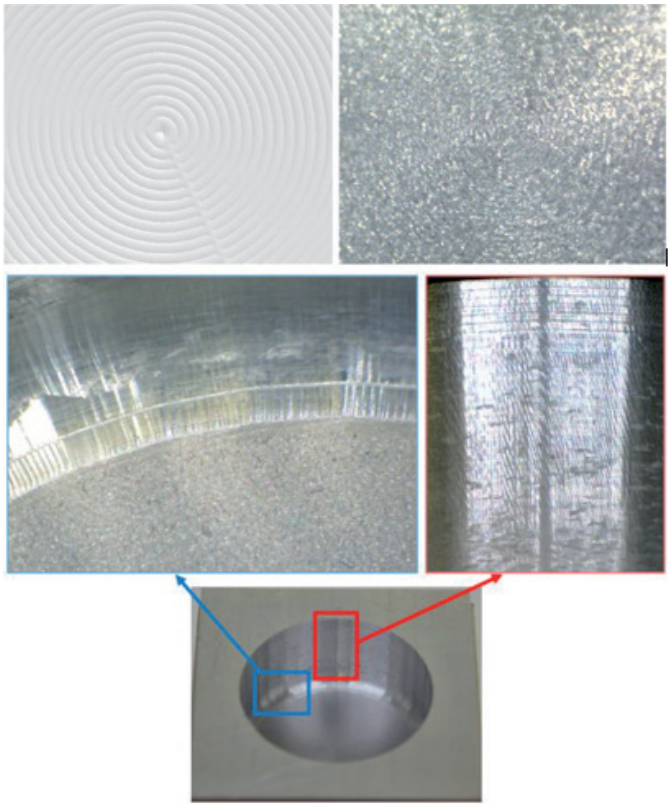

Figure 4: Machined surface after pocket finishing - Constant Z strategy (magnification 20x).

Constant Step - pocket

The tool begins the finishing operation from the top of the pocket and progressively moves towards the bottom of the formed paths. Pocket bottom machining in this strategy is like the abovementioned finishing strategy, from the bottom of the strategy to its centre, Fig. 5.

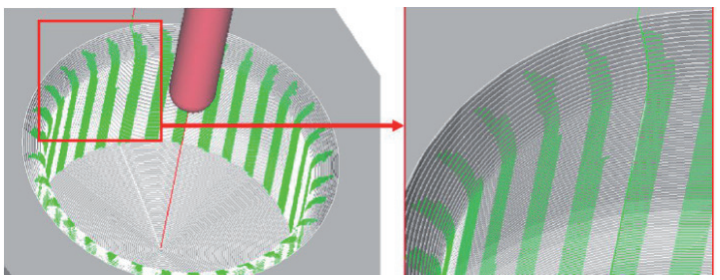

Figure 5: Tool toolpath for finishing operation - Constant step - pocket. 
The comparison between simulation results obtained in CAM system SolidCAM and experimental results of machined surface is shown in Fig. 6.

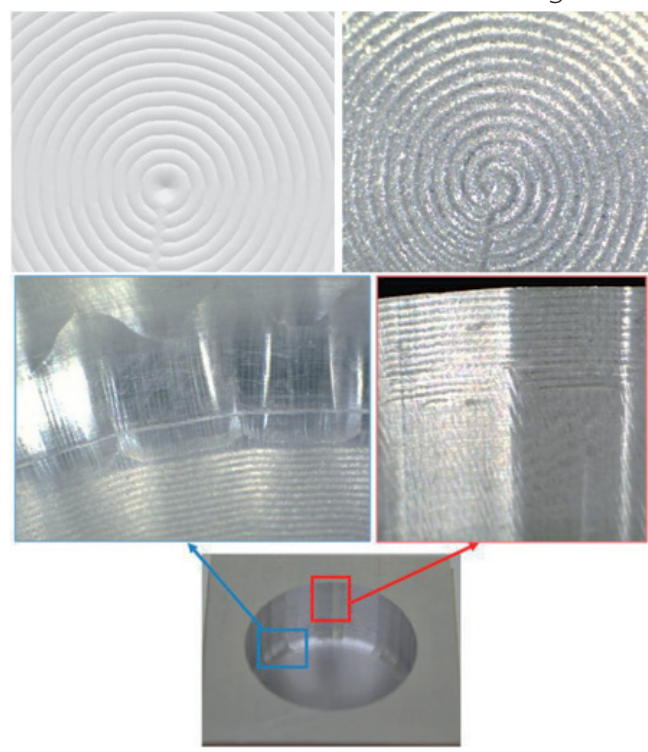

Figure 6: Machined surface after pocket finishing - Constant Step - pocket strategy (magnification 20x).

Constant Step - pocket auto border

Tool gradually moves from the top of the pocket to its bottom, Fig. 7. Tool paths from the edge to centre are generated by concentric circles.

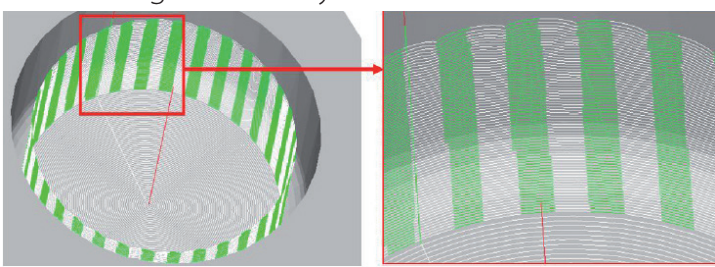

Figure 7: Machined surface after pocket finishing - Constant Step - pocket auto border strategy.

The comparison between simulation results obtained in CAM system SolidCAM and experimental results of machined surface is shown in Fig. 8.

\section{Spiral strategy}

Tool path is a spiral when machining of the pocket periphery. The movement of the tool for this strategy is shown in Fig. 9 and it also is in the form of spiral. Machining of the pocket bottom started from the centre to the border.

The comparison between simulation results obtained in CAM system SolidCAM and experimental results of machined surface is shown in Fig. 10.

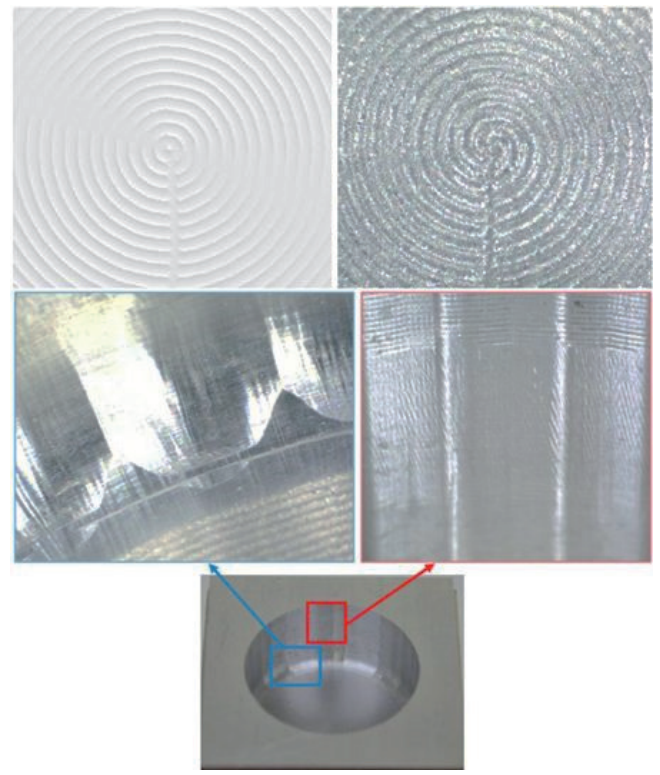

Figure 8: Machined surface after pocket finishing - Constant Step - pocket auto border strategy (magnification 20x).

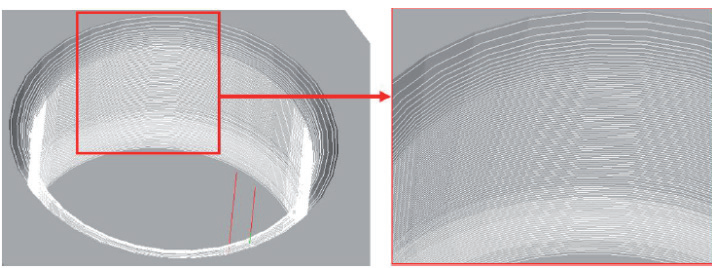

Figure 9: Machined surface after pocket finishing - Spiral.

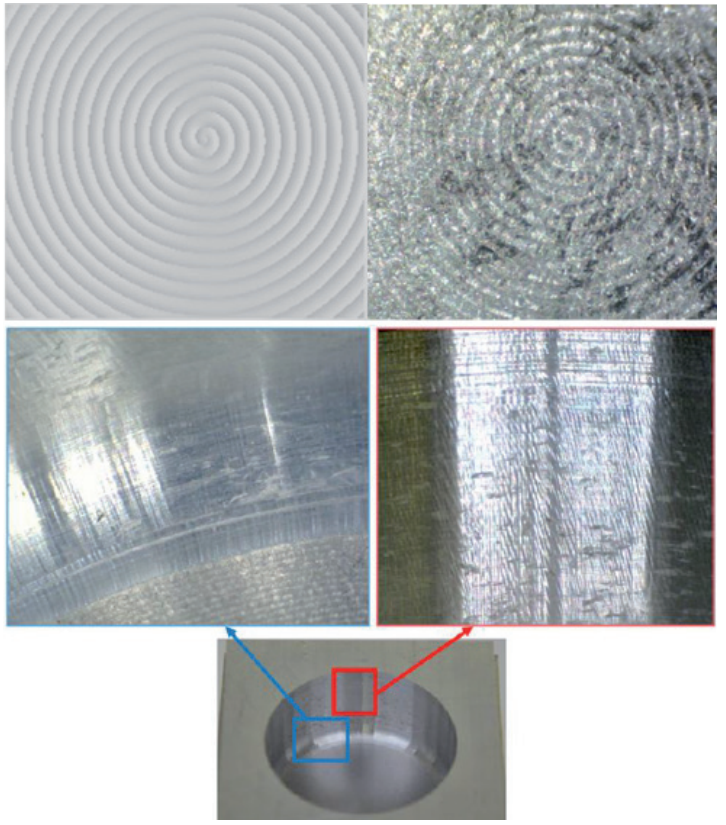

Figure 10: Machined surface after pocket finishing - Spiral strategy (magnification 20x). 


\subsection{Measurement of geometric characteristics}

In the first step, the measurement of surface quality obtained from CAM software was conducted. After that, geometric characteristics of the produced part were measured with the use of CMM device which is shown in Fig.11.
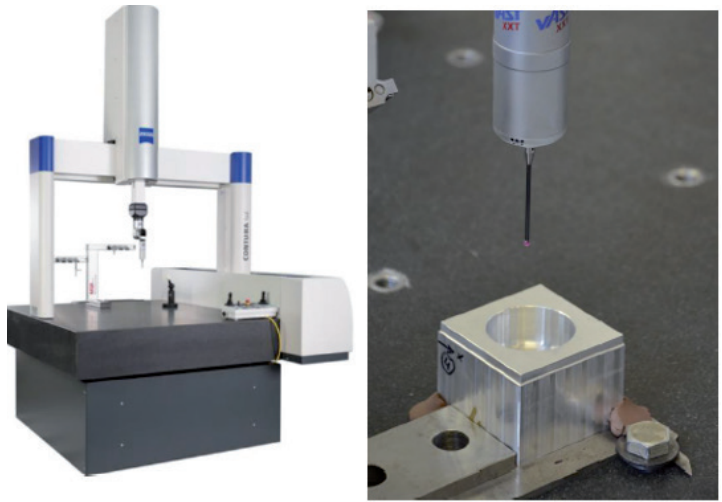

Figure 11: CMM device.

The CMM device Carl Zeiss Contura G2, this machine is equipped with a Carl Zeiss Vast XXT scanning sensor, which can be used for measurement in different positions. For measurement of the geometric characteristics following surfaces were chosen, Fig. 12.

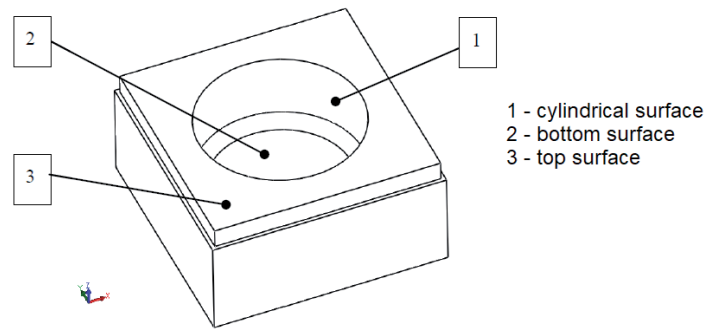

Figure 12: Surfaces used for measuring geometric characteristics.

The measurement was carried out by means of a touch probe with a diameter of $3 \mathrm{~mm}$, which is placed on a carbon arm with a length of $50 \mathrm{~mm}$. The coordinate measuring device used Calypso evaluation software. The software offers evaluation using simple geometric shapes such as circles, cones, cylinders, planes and the others. The measurement of the cylindrical part of the component by the scanning sensor was realized by means of a circle strategy on 10 circular paths. The first lane was moved $1.5 \mathrm{~mm}$ from the base. The following tracks were also $1.5 \mathrm{~mm}$ apart.

When measuring the bottom of the component, a circular measurement strategy was used as well.
With the Calypso program, 11 concentric circular paths with $\varnothing 3, \varnothing 6, \varnothing 9, \varnothing 12, \varnothing 15, \varnothing 18, \varnothing 21, \varnothing$ $24, \varnothing 27, \varnothing 30$ and $\varnothing 33 \mathrm{~mm}$ have been created and used for measuring the bottom surface [8]. The circular paths for measurement cylindrical and bottom surface are shown in Fig. 13.

In order to evaluate the straightness of the
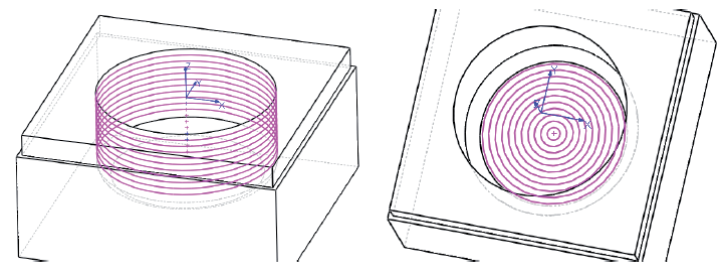

Figure 13: Circular paths for measurement cylindrical and bottom surface.

cylindrical surface of the pocket a measurement strategy for measuring the straightness used straight lines. Four lines were selected in different positions which are shown in Fig. 14. The beginning of all lines starts from $1.5 \mathrm{~mm}$ depth from the top and end is $13.5 \mathrm{~mm}$ depth from the top.

The measurement was carried out by the means

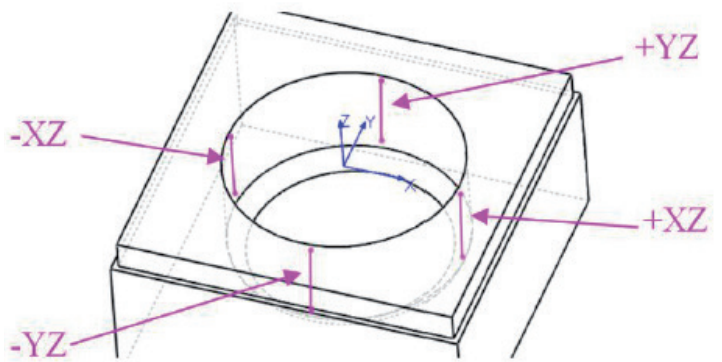

Figure 14: Measuring scheme for measuring straightness of the cylindrical surface.

of a probe sensor. This sensor during measurement of the cylindrical part performed circular paths at certain depths. The measurement strategies were defined by the Calypso measuring software and evaluation program. In order to achieve a complete evaluation, it was necessary to determine the reading device paths in four programs in the software. From the measured data, the results were obtained for shape deviations, roundness and cylindricity.

\subsubsection{Shape deviations}

The evaluation is at 100:1 scale and its title name in program Calypso was RON_circle_05_Isq. Identification RON circle means the measurement of the roundness, 05 denotes the measured circle 
and Isq expresses the evaluation by the interlaced central circle. The resulting deviations from the ideal area is shown in Fig. 15 which displays of the resulting deviations from the areas in the 5th measured circle comparison for different path strategies. Red colour indicates positive deviations and green indicates negative deviations. Positive deviations express the rest material and negative one the undercuts. The measuring probe measured 1316 points in all 10 circles at different heights.
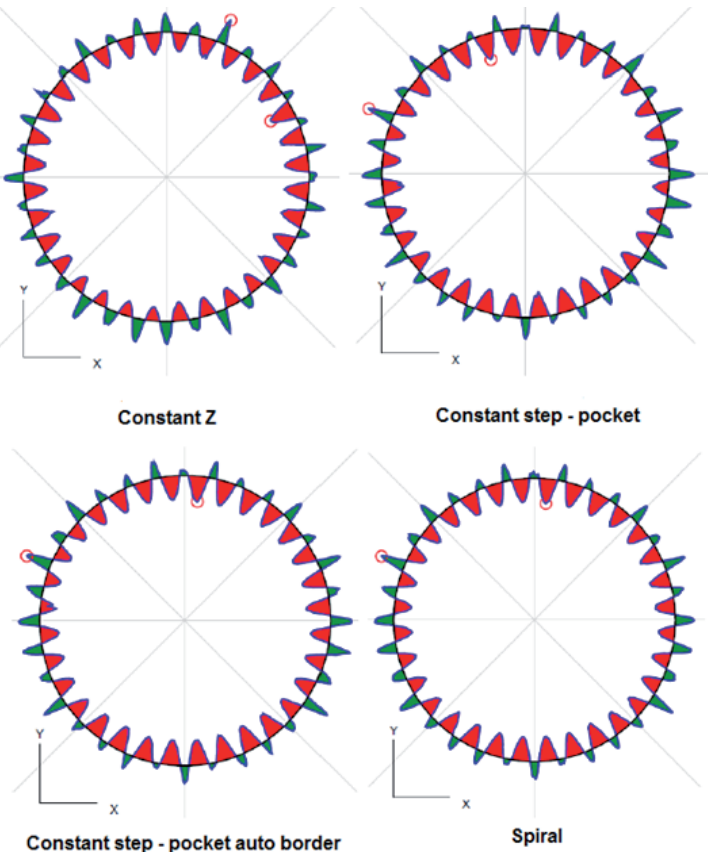

Constant step - pocket auto border

Figure 15: Comparison of resulting deviations of shape.

The maximum measured deviations from the diameter $\varnothing 40 \mathrm{~mm}$ in different measured heights are displayed in Tab. 3.

Table 3: Maximum measured deviations from diameter $40 \mathrm{~mm}$

\begin{tabular}{|l|l|l|l|l|}
\hline Path & Constant Z & $\begin{array}{l}\text { Constant } \\
\text { step - pocket }\end{array}$ & $\begin{array}{l}\text { Constant step - } \\
\text { pocket auto border }\end{array}$ & Spiral \\
\hline 1 & 0.0927 & 0.0901 & 0.0876 & 0.8830 \\
\hline 2 & 0.0848 & 0.0909 & 0.0821 & 0.0872 \\
\hline 3 & 0.0876 & 0.0909 & 0.0888 & 0.0874 \\
\hline 4 & 0.0870 & 0.0906 & 0.0897 & 0.0881 \\
\hline 5 & 0.0872 & 0.0907 & 0.0889 & 0.0886 \\
\hline 6 & 0.0854 & 0.0895 & 0.0876 & 0.0890 \\
\hline 7 & 0.0854 & 0.0889 & 0.0876 & 0.0894 \\
\hline 8 & 0.0871 & 0.0918 & 0.0891 & 0.0893 \\
\hline 9 & 0.0855 & 0.0869 & 0.0864 & 0.0899 \\
\hline 10 & 0.0862 & 0.0853 & 0.0875 & 0.0842 \\
\hline
\end{tabular}

Similar deviation results were obtained for all toolpath strategies used in experiment. The smallest shape deviations were obtained by using Constant Z strategy.

\subsubsection{Roundness}

The measured roundness is shown in Fig. 16 with a 100x magnification. The title name RON_circle_05_ upr4 was used for the evaluation of roundness. A sign upr4 expresses the UPR (Undulation per Revolution) filter. This filter represents an optimization for dimension control, with the number of waves selected per revolution, in this case it was four undulations.

For comparison, the 5th measured circle was chosen. Deviations from the roundness for all manufactured samples shows Fig. 16. The highest roundness deviations of the components using the UPR filter are shown in the Tab.4. Deviations from the roundness for all manufactured samples shows Fig. 16. The highest roundness deviations of the components using the UPR filter are shown in the Tab.4.

When evaluating the pocket roundness, the measured data from 10 circles were used, as in determining the shape tolerance. The measured roundness deviations are shown in Fig. 16 at 20x magnification. The green colour shows deviations of the cylindrical shape from the ideal shape

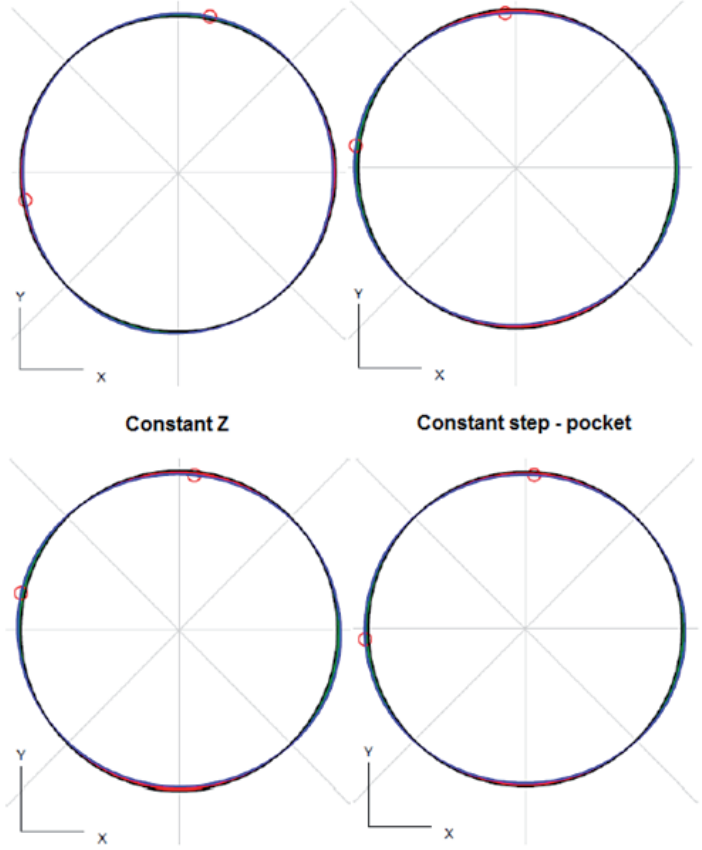

Figure 16: Roundness deviations using UPR filter. 
when measured on individual circular paths. For all samples, the $Y$-axis deviation is positive and is negative in the $X$-axis. The measured data in all 10 circles show the similar trend for each component. The smallest deviations of roundness were obtained for the sample produced by Constant Z milling strategy.

Table 4: Comparison of largest roundness deviations using UPR filter

\begin{tabular}{|l|l|l|l|l|}
\hline Path & Constant Z & $\begin{array}{l}\text { Constant } \\
\text { step - pocket }\end{array}$ & $\begin{array}{l}\text { Constant step - } \\
\text { pocket auto border }\end{array}$ & Spiral \\
\hline 1 & 0.0093 & 0.0123 & 0.0129 & 0.0124 \\
\hline 2 & 0.0091 & 0.0140 & 0.0132 & 0.0106 \\
\hline 3 & 0.0088 & 0.0138 & 0.0129 & 0.0125 \\
\hline 4 & 0.0092 & 0.0130 & 0.0131 & 0.0120 \\
\hline 5 & 0.0093 & 0.0131 & 0.0131 & 0.0117 \\
\hline 6 & 0.0095 & 0.0134 & 0.0132 & 0.0119 \\
\hline 7 & 0.0098 & 0.0153 & 0.0137 & 0.0119 \\
\hline 8 & 0.0103 & 0.0176 & 0.0162 & 0.0124 \\
\hline 9 & 0.0109 & 0.0142 & 0.0140 & 0.0128 \\
\hline 10 & 0.0112 & 0.0142 & 0.0143 & 0.0130 \\
\hline
\end{tabular}

\subsubsection{Cylindricity}

When evaluating the pocket cylindricity, the measured data from 10 circles were used for determining the shape tolerance. The measured cylindrical deviations are shown in Fig. 17 at 20x magnification. When measuring cylindricity, the outer circle represents measurement along the first circular path. The green colour shows cylindricity deviations from the ideal shape, which were
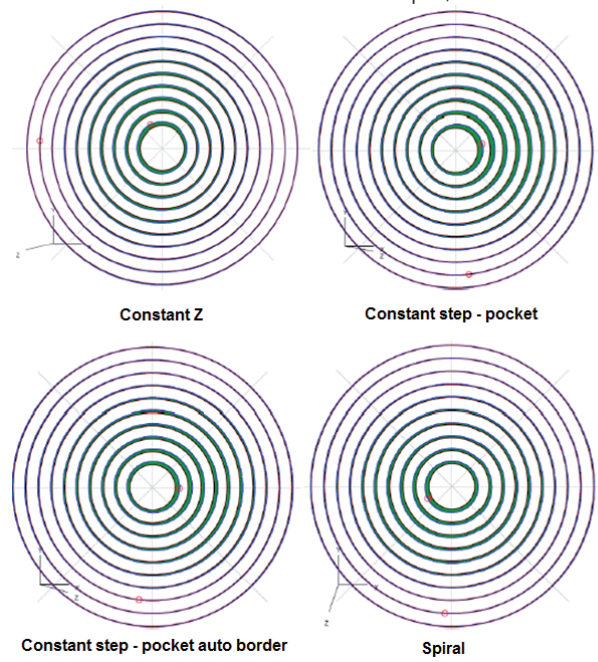

Figure 17: Cylindricity deviations pocket. measured on all individual circular paths.

With greater measuring depths, the deviations of cylindricity increases, this effect is shown in Fig. 18. CYL_mie_f_upr4 has been used in the Calypso cylindrical evaluation. This title name represents CYL cylindrical shape by using the MIE inscribed shape, where a 4-wave UPR filter was used per revolution. Similar results of cylindricity were obtained with the use of Constant Step - pocket strategy and Constant Step - pocket auto border strategy.

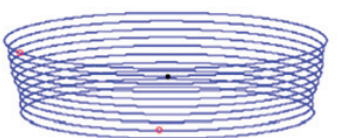

Constant Z

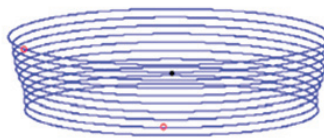

Constant step - pocket auto borde

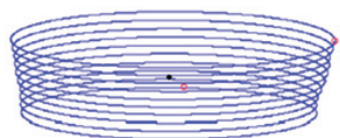

Constant step - pocket

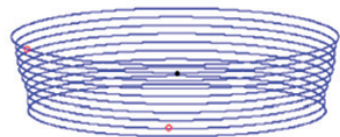

Spiral
Figure 18: Cylindricity deviations of the pocket from periphery view.

The smallest cylindricity deviation had the sample produced by the Constant Z strategy. Cylindricity deviations are also figured in Fig. 18, where at the top of the pocket is the smallest deviation of the shape and at the bottom the largest deviation. Tab. 5 shows the comparison of the pocket diameter of individual components at a depth of $13.5 \mathrm{~mm}$ measured from the top of the part.

Table 5: Comparison of pocket diameter accuracy at the depth $13.50 \mathrm{~mm}$ from the top.

\begin{tabular}{|l|l|l|l|l|}
\hline & Constant Z & $\begin{array}{l}\text { Constant step } \\
- \text { pocket }\end{array}$ & $\begin{array}{l}\text { Constant step } \\
- \text { pocket auto } \\
\text { border }\end{array}$ & Spiral \\
\hline $\begin{array}{l}\text { Average } \\
{[\mathrm{mm}]}\end{array}$ & 39.935 & 39.927 & 39.932 & 39.927 \\
\hline
\end{tabular}

According to the measured results given in Tab. 5 the smallest deviation of diameter was obtained for samples which were manufactured with the use of Constant Z and Constant Step - pocket auto border strategies. For these samples, the measured diameter is the same. Also, the same is the measured diameter for the components produced by the Constant Step - pocket and Spiral strategy.

\section{Conclusions}

In this study, the influence of different milling strategies on surface quality and geometrical characteristics were evaluated and analysed. For 
roughing and semi finishing, the same strategies have been chosen for all manufactured samples. Each sample was finished by different finishing strategies - Constant Z, Constant Step - pocket, Constant Step - pocket auto border and Spiral strategy.

Geometrical characteristics obtained from SolidCAM were compared with the experimental ones. Similar geometrical characteristics were achieved for all manufactured parts from the milling simulation. The resulting bottom surface of the pocket is affected by the tool paths.

The main aim of the article was evaluation of the geometrical characteristics - roundness, cylindricity and shape deviations which were measured by CMM device Carl Zeiss Contura G2.

For shape deviations similar results were obtained for all toolpath strategies used in experiment. The smallest shape deviations were obtained by using Constant Z strategy. The highest roundness deviations of the components were obtained using strategy Constant Step - pocket and the lowest roundness deviations were achieved by strategy Constant Z. Constant Step - pocket strategy and Constant Step - pocket auto border strategy shown similar results of cylindricity. The smallest cylindricity deviation had the sample produced by the Constant Z strategy. Cylindricity deviations at the top of the pocket had the smallest deviation of the cylindricity. In comparison, the bottom had the largest deviation.

The experimental results showed the effects of milling strategies of the surface quality. The pocket bottom surface was influenced by the toolpath strategies. The best surface quality (roundness, cylindricity, shape deviation) was achieved by the Constant $Z$ tool path strategy. From above mentioned results it can be recommended that, the milling strategy Constant $Z$ is suitable for achieving optimal surface quality for milling pockets.

\section{Acknowledgments}

This publication was supported by the Operational Programme Research and Innovation for the project: Research into NewGeneration Materials, Structures, and Technologies for Industrial Production in the 21st Century, ITMS+ 313010T594, co-funded by the European Union from the European Regional Development Fund.

This research work was also supported by the project VEGA no. 1/0441/17 "Application equipment's for car body surface parts".
We thank unknown reviewers for valuable recommendations of text improvement

\section{References and Notes}

[1] Ižol, P., Beňo, J. and Mikó, B.: Precision and Surface Roughness When Free-Form-Surface Milling. Výrobné inžinierstvo, 2011, Vol.10, No.1., pp 7073. ISSN 1335-7972

[2] Mikó, B., Beňo, J., Ižol, P. and Maňková, l.: Surface quality of sculpture surface in case of 3D milling. In: Nástroje: sborník přednášek, ITC 2011: 24. - 25.5.2011, Zlín. - Zlín, 2011, 6 p. ISBN 978-80-7454-026-4

[3] Ižol, P., Varga, J.: Porovnanie CAM stratégií obrábania pri 2.5D frézovaní. Transfer inovácií, 2011, No.19., pp 1021053. ISSN 13377094

[4] Romeroa, P.E., Doradoa, R., Díaza, F.A., Rubio, E.M.: Influence of pocket geometry and tool path strategy in pocket milling of UNS A96063 alloy. The Manufacturing Engineering Society International Conference, MESIC 2013, Procedia Engineering 63, 2013, pp 523531

[5] Hatna, A., Grieve, R.J., Broomhead, P.: Automatic CNC milling of pockets: geometric and technological issues. Computer Integrated Manufacturing System, 1998, Vol.11, No.4., pp 309330

[6] Choi, B.K., Kim, B.H.: Die-cavity pocketing via cutting simulation. Computer Aided, 1997, Vol.29, No.12., pp 837846

[7] Ižol, P., Tomáš, M., Beňo, J.: Milling strategies evaluation when simulating the forming dies' functional surfaces production. Open Engineering. 2016, Vol.6, No.1., pp 98105. ISSN 2391-5439

[8] Mikó B.; Farkas G.: Comparision of flatness and surface roughness parameters when face milling and turning; Development in machining technology Vol.7. pp.18-27. Ed.: W. Zebala, I. Manková; Cracow University of Technology, Cracow 2017. ISBN 978-80-5533193-5

[9] Gapinski B.; Grzelka M., Rucki, M.: The accuracy analysis of the roundness measurement with coordinate measuring machines. XVIII Imeko World congress, Metrology for a Suistainable Development, September, 17 - 22, 2006, Rio de Janeiro, Brazil

[10] Zheng, P., Wu, J., Zhang, L.: Research of the On-Line Evaluating the Cylindricity Error Technology Based on the New Generation of GPS. 13th Global Congress on manufacturing nad Management, GCMM 2017, Procedia Engineering 174 (2017) $402-409$

[11] Nadolny. K., Kaplonek, W.: Analysis of Flatness Deviations for Austenitic Stainless Steel Work-pieces after Efficient Surface Machining, MEASUREMENT SCIENCE REVIEW, Volume 14, No. 4, 2014.

[12] Salah, A., Mohamd, O.: Dimensional and Geometrical Form Accuracy of Circular Pockets Manufactured for Aluminum, Copper and Steel Materials on CNC Milling Machine using CMM, International Journa of Engineering Research in Africa Vol. 17 (2015) pp 64-73 Online: 2015-07-15, (2015) Trans Tech Publications, Switzerland 